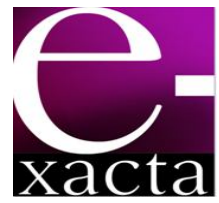

ISSN: 1984-3151

\section{INTERATIVIDADE E COMPLEMENTARIDADE: O USO DE PROJETOS NAS AULAS DO CICLO BÁSICO DAS ENGENHARIAS}

\author{
INTERACTIVITY AND COMPLEMENTARITY: USING PROJECTS IN \\ ENGINEERING BASIC CYCLE
}

\author{
Wagner Marcelo Pommer'; Clarice Peres Carvalho Retroz Pommer ${ }^{2}$ \\ 1 Doutor em Educação, FEUSP, 2012. Professor de Ensino \\ Superior - UNINOVE. São Paulo, SP.wmpommer@usp.br. \\ 2 Mestre em Psicologia. UNIMARCO, 2005. Professora da \\ Escola de Aplicação/FEUSP. São Paulo, São Paulo. \\ claricepommer@usp.br.
}

Recebido em: 25/12/2012 - Aprovado em: 20/04/2013 - Disponibilizado em: 11/06/2013

\begin{abstract}
RESUMO: Naturalmente, é próprio das Engenharias desenvolverem projetos aplicados às disciplinas específicas, de modo a produzir relatórios técnicos especializados. Frente à necessária expectativa de que as universidades cultivem profissionais com qualidade, abre-se espaço para discutir o papel formativo das disciplinas dos cursos das Engenharias. Uma das possibilidades consiste em articular competências e conhecimentos no ciclo básico, associados ao desenvolvimento de projetos educativos. A efetivação dos projetos educativos na sala de aula dos cursos de Engenharia possibilita a interatividade do aluno, que deve ser acompanhada e valorizada pela reflexão, situando uma ação complementar que promova desafios. Este artigo relata as etapas de desenvolvimento de um projeto que objetivou a confecção e construção de uma bomba eólica, inserida num contexto de desafio aos alunos. No desenvolvimento das etapas do referido projeto educativo, os alunos vivenciaram a interatividade e a complementaridade, processos fundamentais para alavancar o ensino e a aprendizagem. Foi observado que $o$ projeto educativo favoreceu a interatividade com os conhecimentos científicos desenvolvidos nas diversas disciplinas, num contexto complementar com o ambiente técnico e tecnológico, possibilitando a imersão dos alunos envolvidos em uma dimensão qualitativa e criteriosa, quadro que favorece o desenvolvimento de habilidades e competências básicas para um futuro engenheiro.

PALAVRAS-CHAVE: Interatividade. Complementaridade. Projetos educativos. Ensino de engenharia.
\end{abstract}

ABSTRACT: Naturally, it is typical from Engineering to develop projects applied in specific disciplines, in a way to produce specialized technical reports. Facing the required expectation from Universities to prepare quality professionals, it opens up space to discuss the formative role of engineering courses disciplines. One possibility is to articulate skills and knowledge in the basic cycle, associated with developing educational projects. The use of educational projects in classroom engineering courses enables student interactivity, which must be associated and valorized by reflection, establishing a complementary action that promotes challenges. This paper reports the developing stages of and educational project that aimed to create and construct a wind pump, inserted in a challenging context to the students. In the intermediate stages of this educational project, students experienced interaction and complementarity, fundamental processes to leverage teaching and learning. We observed that the educational project favored interactivity with scientific knowledge developed in the different disciplines, in a complementary context with technical and technological environment, enabling students' immersion in a qualitative and judicious dimension, framework that encourages the development of skills and essential competences to a graduated engineer.

KEYWORDS: Interactivity. Complementarity. Educative Projects. Engineering Teaching. 


\section{INTRODUÇÃo}

Em nível universitário há incessantes discussões envolvendo o processo de formação dos graduandos, especialmente após a inquietação originada pelas avaliações governamentais em torno da qualidade de ensino das Instituições de Ensino Superior (IES).

Krasilchik (2008) destaca que os modelos de pouca flexibilidade usualmente encontrados nas Instituições de Ensino Superior favorecem um quadro de tensões que demandam certas mudanças em alguns níveis, como o curricular, o epistemológico e o didático.

As Diretrizes Curriculares Nacionais destacam a necessidade de incrementar a Educação Profissional, almejando o desenvolvimento da capacidade de:

[...] mobilizar, articular e colocar em ação conhecimentos, habilidades, atitudes e valores necessários para o desempenho eficiente e eficaz de atividades requeridas pela natureza do trabalho e pelo desenvolvimento tecnológico (BRASIL, 2002, p. 37).

Com relação às possíveis mudanças no plano didático, este texto utilizou fundamentação do ensino básico, mas cabível para as instituições de ensino superior. Esta extensão visou fomentar condições para 0 aluno negociar os significados dos conhecimentos, num contínuo modo do 'aprender a aprender', que Delors (2003) aponta como um dos quatro pilares da Educação.

Pozo (1998) acrescenta que o 'aprender a aprender' permite aos alunos exercitar a capacidade de:

[...] enfrentar situações e contextos variáveis, que exijam deles a aprendizagem de novos conhecimentos e habilidades. Por isso, os alunos que hoje 'aprenderem a aprender' estarão, previsivelmente, em melhores condições de adaptar-se às mudanças culturais, tecnológicas e profissionais que nos aguardam na virada do milênio (POZO, 1998, p. 9).

Em nível superior, um importante desafio se situa em priorizar a articulação entre conhecimento e competência. Para tal, os conteúdos e as disciplinas se constituem em meios para o desenvolvimento de competências essenciais.

Considerando-se as finalidades majoritárias do ambiente universitário - o ensino, a pesquisa e a extensão - uma ferramenta adequada para mobilizar esse tríplice eixo é priorizar na formação do aluno situações que complementem a aquisição de conhecimentos fundamentais, a preparação científica e a capacidade de uso das tecnologias disponíveis.

Em sintonia com tais propostas, há algumas reflexões concebendo o conhecimento como um novo fator de produção, conforme Machado (2009), visto que, nos tempos atuais, há forte imbricação dos universos do conhecimento e do trabalho.

Numa primeira aproximação, Boisot (2000) descreve como se atribui valor ao conhecimento, no terreno da economia, propondo uma analogia com o espaço geométrico: um ponto com três dimensões ou eixos.

Boisot (2000) representa no primeiro eixo a dimensão abstrato/concreto. Esse autor pondera que um bem tem valor maximizado se puder ser aplicado a múltiplos contextos. Essa posição equivale a conceber que o conhecimento abstrato amplia as possibilidades de estabelecer relações e composições, de modo a evitar o reducionismo a um único contexto, que desvaloriza o conhecimento.

O referido autor aponta um segundo eixo: a dimensão não-codificado/codificado. Para Boisot (2000), a codificação valoriza o conhecimento, pois viabiliza a socialização em termos públicos. O conhecimento que se apóia exclusivamente na prática ou experiência, sem o uso dos inúmeros meios de representação, torna limitada a possibilidade de diálogo ou transferência para outras pessoas.

Boisot (2000) aponta um terceiro eixo: a dimensão difundido/não-difundido. Quanto menos difundido, maior é a possibilidade de exploração mercadológica 
de um bem, o que pode provocar interesse ou demanda pelo objeto.

Porém esse ponto de vista econômico implica desdobramentos no terreno educativo, particularmente no que tange a questão da concepção, apresentação e produção do conhecimento no ambiente universitário.

No universo educativo, conforme aponta Machado (2004), o conhecimento é um bem pessoal, que valoriza quem o possui, tornando supérflua a noção de objetivação fora da pessoa que o produz. Para o autor, o conhecimento é um bem que não se gasta, muito ao contrário, que se renova pelo uso, permitindo um aprimoramento contínuo do indivíduo, incentivando a formação do valor social de laço, efetivado pela circulação pelos diversos meios de comunicação, incentivando a construção coletiva do conhecimento.

Em síntese, este texto objetivou discutir o projeto educativo no Ensino Superior considerando como parâmetros a interatividade e a complementaridade, dois referenciais que permitem regular a aquisição de conhecimentos articulados ao desenvolvimento de competências discentes. No decorrer do artigo, foram realizadas as objetivações destes referenciais, ilustrando alguns resultados de um projeto abordado nas aulas de Física Geral e Experimental III.

\section{Projetos: Um CENÁRIO INTERATIVO ENTRE INFORMAÇÃO E CONHECIMENTO}

Para encaminhar as reflexões sobre os dois conceitos norteadores para as ações discentes em sala de aula a interatividade e a complementaridade - delineou-se um quadro para conceituar e articular o cenário das informações e conhecimentos, inseridas num ambiente de formação de competências para o mercado de trabalho, ciência e tecnologia.

Na raiz etimológica, o termo 'interatividade' se aglutina pela justaposição do prefixo latino inter (posição intermediária) e o sufixo ativo, do latim activu, remetendo ao ser que age e está de prontidão. Desse modo, o presente texto delimita interatividade como a capacidade de prontidão na interação.

Machado (2004) aponta que na sociedade pósmoderna, mais do que nunca, os diversos ambientes estão impregnados de tecnologias, agregando uma infinidade de dados.

Inicialmente, buscou-se tecer esclarecimentos básicos para fundamentar uma abordagem que permitisse estabelecer relações com os projetos educativos em nível de Ensino Superior e o desenvolvimento articulado entre informação e conhecimento, associado e complementado pela possibilidade de aprimorar competências.

Em vista disso, uma primeira reflexão necessária envolveu a delimitação de três termos: dado, informação e conhecimento.

Por 'dado' entende-se um conjunto de valores ou elementos que estabelece um estado de certo sistema. Existem vários bancos de dados, disponíveis em setores de arquivamento e centros de memória.

Porém, um banco de dados tem serventia somente se alguém se mobiliza para buscar algo. Algum observador que possui algum critério de seleção pode rebuscar um banco de dados, tendo como base alguma expectativa ou condição.

Essas modificações absorvidas são denominadas 'informações', que subtraem, filtram e procuram por padrões básicos nos dados, por uma observação direta, estabelecendo uma relação entre coisas e agentes, tendo a capacidade de consolidar ou aceitar modificações na chegada de novas informações. Com toda certeza, a informação se consolidou como uma necessidade na vida moderna.

Para Boisot (2000), o 'conhecimento' é resultante de uma série de expectativas que um observador tem

e-xacta, Belo Horizonte, v. 6, n. 1, p. 9-18. (2013). Editora UniBH Disponível em: www.unibh.br/revistas/exacta 
com respeito a diversas informações ou eventos. É uma disposição de agir em um modo que utiliza $o$ ato cognitivo, que busca inferir algo, ato que vai além da simples observação e manipulação direta.

Boisot (2000) propõe que o conhecimento otimiza e economiza recursos físicos na medida em que:

- é incorporado nos produtos ou processos;

- organiza os produtos ou processos pelo uso de informação codificada e simbólica;

- caracteriza compreensão dos agentes que interagem com os produtos.

Outro autor, Roszak (1988), coloca a informação como pequenos pacotes de fatos, descontínuos, que podem ser úteis se for sobreposto o pensar. A mente pensa com ideias, ou seja, com o contexto relacional entre dados e informações que fazem significado. Nesse sentido, as ideias "[...] só podem ser criadas, alteradas e suplantadas por outras ideias. [...] A principal tarefa da educação é, portanto, ensinar os jovens a lidar com ideias" (ROSZAK, 1988, p. 140).

O autor coloca a generalização como ação básica da inteligência, permitindo articular informações, dentro de uma gama situada entre a abundância e a quase ausência, para a procura de algum padrão. "As ideias são padrões reguladores que satisfazem a mente quando ela pergunta: o que isso significa? Sobre o que estamos falando?" (ROSZAK, 1988, p. 143).

Roszak (1988) afirma que as ideias são padrões que permitem declarar o significado das coisas e objetos, organizando-se a partir da experiência e das revelações que iniciam um processo cognitivo para aprimorar o conhecimento. Nesse sentido, a mente:

[...] é naturalmente uma fiandeira de projetos, estabelecendo objetivos, escolhendo-os entre as muitas alternativas do que poderíamos estar fazendo de nossas vidas. [...] Pensar significa constituir projetos e refletir sobre os valores que cada projeto envolve (ROSZAK, 1988, p. 319).

Machado (2004) sustenta que, em certo sentido, conhecer é acumular, mas isso é insuficiente para conhecer. Assim, o conhecimento não pode ser confundido com o acúmulo de dados ou informações que abundam nos meios de comunicação. Para o autor, o conhecimento se associa à inteligência, assim como os dados se associam às informações.

Ampliando essa ideia, Machado (2004) aponta que conhecer é tecer os nós de uma rede de significações, que possui múltiplos percursos, relacionando temas tácitos e explícitos.

Se for considerado um contexto interativo, o conhecimento é um bem que quanto mais se usa melhor fica, articulando dados e informações, pensamentos e ideias. Esses modos complementares de manifestações da formação do conhecimento fluem como se fossem enredados, permitindo uma tessitura e composição dialética, cujo uso constante ciclicamente renova o conhecimento.

Numa segunda reflexão, Roszak (1988) define experiência como o curso existencial que molda o 'self' no decorrer do tempo, sendo matéria-prima para cultivar valores. Para isso, o ser humano faz uso da memória, o 'local' de registro das experiências que assume a forma de padrões de guia e conduta, que não tem analogia direta com a memória do computador, apesar de insistentes aproximações feitas pelo senso comum.

As considerações tecidas até o momento permitem delimitar uma caracterização do termo 'complementaridade'. A partir de Roszak (1988), concebeu-se complementaridade como a capacidade de alguns contextos ou instrumentos em beneficiar a busca de informações e a articulação com os conhecimentos tratados nas diversas situações de sala de aula, de modo a favorecer um espaço para a necessária mobilização de competências discentes.

Com suporte nas deliberações situadas anteriormente, pontua-se neste texto que a viabilização de projetos em sala de aula se constitui em contexto propício para 
o exercício da complementaridade. Nesse sentido, o projeto educativo encaminha meios de prover acesso às informações. De modo análogo, a porta que se abre para as possíveis articulações que permitem construir o conhecimento através do enredar, do tecer os nós de uma rede de significações, que, nem sempre, o aluno consegue percorrer com recursos próprios.

Seguindo tais parâmetros, numa outra acepção metafórica, o projeto educativo age como se fosse um catalisador de objetivos e metas. Para atingir os resultados propostos em determinado projeto, os alunos buscam acesso a múltiplos recursos, como dados, informações e conhecimentos, situações que podem fomentar competências, num contexto interativo e complementar.

Considera-se também o fato de o projeto permitir a retroação que, quando associada à natural comunicação entre alunos, possibilita a interação autônoma do aluno para consolidar as metas. Este outro patamar caracteriza, de maneira instigante, um modo complementar de realizar uma abordagem educativa e qualitativa em sala de aula.

\subsection{O PROJETO COMO SUPORTE PARA AÇÕES EDUCATIVAS NAS UNIVERSIDADES}

Ainda é comum no meio educacional uma concepção de aprendizagem exclusiva de conceitos, como se conhecer fosse somente acumular informações. Além disso:

[...] ser inteligente implicava articular logicamente ideias, estar informado sobre grandes conhecimentos, enfim, adquirir como discurso questões presentes principalmente em textos eruditos e importantes. Nesses termos, dar aula podia ser para muitos professores um exercício intelectual muito interessante. O problema é que muitos alunos não conseguem aprender nesse contexto, nem se sentem estimulados a pensar, pois sua participação nesse tipo de aula não é tão ativa quanto poderia ser (MACEDO, 2006, p. 17).
Diante da possibilidade e necessidade de aproximar o trabalho desenvolvido pelas Instituições de Ensino Superior com as atividades do futuro campo de trabalho dos graduandos e da pesquisa acadêmica, este texto fez referência ao projeto, delineado por Macedo (2006). A opção pelo trabalho com projetos se fez como um dos possíveis modos para desencadear ações discentes para exercitar a articulação entre conceitos e competências diversas.

Boutinet (2002) aponta no projeto três elementos constituintes: a relação com o futuro, a abertura para o novo e o caráter indelegável da ação projetada.

No primeiro aspecto, o ato de projetar implica a possibilidade de um futuro a ser construído e concretizado, transformado em real a partir de uma ilusão, o que configura uma posição de aflorar o potencial latente dos alunos através de uma idealização ou de uma meta a ser transformada em ação.

Quanto à segunda característica, o projeto implica a incerteza e relatividade do sucesso, que precisa ser considerado no processo de construção da articulação entre conhecimento e competência. Em um projeto educativo, deve haver meio e espaço para orientar os interesses e as metas a serem alcançadas, inserindo os alunos num jogo para a busca de soluções para os problemas inerentes aos projetos. Em síntese, os projetos apresentam como ingrediente básico a incerteza de resultados e a intuição do melhor caminho a ser trilhado para atingir os objetivos educativos.

Um último ponto a se considerar é que o projeto propicia ao aluno a ação principal e primordial, sob a orientação do professor. Em relação à natureza educacional do projeto em questão, a parceria entre aluno e professor implica papeis claros, delimitados e complementares na proposta de trabalho com essa modalidade didática em sala de aula.

O ambiente de projeto torna-se convidativo à mobilização. Desse modo, o desafio gerado pela 
confecção de um produto e pelo registro escrito das ações e metas possibilita a abertura de espaço para se trabalhar em conjunto. Outro ponto favorável para o trabalho com projetos é a inovação na busca de conhecimentos orientadores que guiem as tomadas de decisões, configurando um quadro de ações favoráveis à atitude de se transformar como pessoa e profissional.

\subsection{O PROJETO EM CONCEPÇÃO: A CRIAÇÃO E CONSTRUÇÃO DE UMA BOMBA EÓLICA}

Atualmente, nas diversas áreas de conhecimento ocorre uma adesão de inúmeras Instituições de Ensino Superior da rede federal, estadual e particular com relação aos denominados Projetos Integradores, com um enfoque multidisciplinar ou interdisciplinar.

Em diversas instituições, esses projetos fazem parte de um desenvolvimento interdisciplinar. Grande parte das Instituições de Ensino Superior optou por uma forma organizada em horário extra-aula. Em algumas outras universidades, a condução do projeto interdisciplinar é realizada por alguma disciplina da própria grade curricular.

Como ilustração, em nível nacional, ocorre a aplicação de projetos integradores no Instituto Federal de Educação, Ciência e Tecnologia do Rio Grande do Norte, Instituto Federal de Educação, Ciência e Tecnologia de Santa Catarina, Universidade Federal de São Carlos (Centro de Ciências/São Paulo) e Faculdade de Tecnologia do Serviço Nacional de Aprendizagem Industrial (SENAI) (Campo Grande/Mato Grosso do Sul), Faculdade de Tecnologia (FATEC/São Paulo), dentre outras organizações. Os exemplos representam uma preocupação das instituições em oferecer aos alunos uma educação que lhes dê acesso a conhecimentos conceituais, procedimentais e atitudinais, conforme determinação governamental presente nos Diretrizes Curriculares Nacionais, Brasil (2002).
Este texto apresenta 0 relato de um projeto interdisciplinar, conduzido pela disciplina Física Geral e Experimental III. Essa vivência ocorreu no ano de 2010 em uma IES da rede particular, no ciclo básico dos cursos de Engenharia, em uma turma do período noturno, na cidade de São Paulo.

O referido projeto interdisciplinar teve diretrizes gerais definidas pela própria IES e tinha como intenção mobilizar os alunos para a realização de um projeto integrador.

No referido trabalho, a designação foi a criação, planejamento e construção de um sistema cuja principal função era a captação de uma fonte de energia eólica fornecida pela instituição (um ventilador de uso comercial) e a posterior transformação de tal energia em energia mecânica, de modo a bombear certa quantidade de massa de água disponibilizada até determinada altura.

No projeto, intitulado 'Protótipo de uma bomba eólica', a IES considerou como prerrogativa preferencial a utilização de materiais recicláveis para a confecção do produto. $\mathrm{O}$ desafio proposto aos alunos foi coletar o ar de um ventilador comercial, situado em um suporte vertical com cerca de 2 metros de altura.

A tarefa designada foi projetar o produto e participar de um jogo, competição que envolveu seis grupos, compostos de 5 a 8 alunos, avaliados no seguinte aspecto: a partir das regras de concepção do sistema, o vencedor seria o grupo que conseguisse elevar água a uma maior altura, num certo intervalo de tempo.

Como procedimentos básicos, de acordo com Boutinet (2002), a viabilização do projeto solicitou aos alunos:

- planejar as ações, constituindo um mapeamento das trajetórias possíveis e viáveis;

- fazer, executar e colocar em andamento as diversas etapas planejadas; 
- avaliar constantemente, para se necessário replanejar as ações, a fim de atingir as metas eleitas ou, caso necessário, desmembrar ou ampliar as metas iniciais e até mesmo analisar a viabilidade das metas;

- estabelecer indicadores, de modo a auferir e divulgar os resultados parciais ou globais.

Durante o semestre, houve ambiente para discutir as ideias dos alunos com relação às concepções e evoluções do sistema, acompanhamento da execução e andamento do projeto, assim como oportunidades para testar os mecanismos.

Além do texto padrão para a elaboração de um relatório técnico, foi proposta aos alunos a ação de documentar as diversas etapas da evolução do produto.

Essa ação de registro, denominada Memorial, uma manifestação usual e presente em diversos trabalhos acadêmicos, foi caracterizada como um guia do percurso realizado pelos grupos e que permitiu registrar o processo de desenvolvimento das ideias, erros, mudanças e melhorias das diversas concepções do produto e do processo.

\subsection{O PROJETO EM AÇÃO: APLICAÇÃO, ALGUNS RESULTADOS E ANÁLISES}

Para vencer o desafio, os grupos exploraram o desenvolvimento em dois itens: (a) o sistema de coleta do ar proveniente do ventilador; (b) o mecanismo elevatório da água.

\subsubsection{O SISTEMA COLETOR DE ENERGIA EÓLICA}

Para o sistema de coleta de ar, poucos grupos optaram pela confecção de um ventilador. A maioria reutilizou um sistema de pás adquirido em lojas de recicláveis ou desmontaram ventiladores do ambiente de trabalho ou de residências de conhecidos.

A seguir, para ilustrar e ressaltar a importância do memorial para descrever e organizar a evolução das etapas do referido projeto, é apresentado o desenvolvimento do mecanismo coletor de ar do Grupo 1. (Figura 1a)

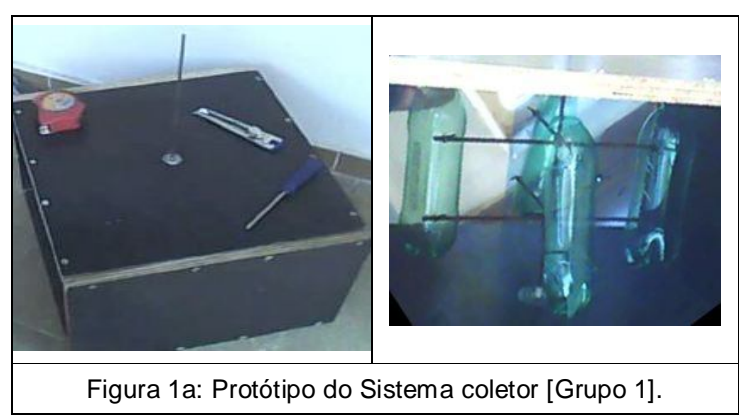

No desenvolvimento do sistema, os alunos do grupo 1 perceberam que ele, originalmente situado no referencial sustentável (caixa de madeira e garrafas PET), não era eficiente para coletar a energia eólica (Figura 1a). Então, optaram por um sistema de pás adquirido de um depósito de materiais recicláveis, que originou a solução final (Figura 1b).

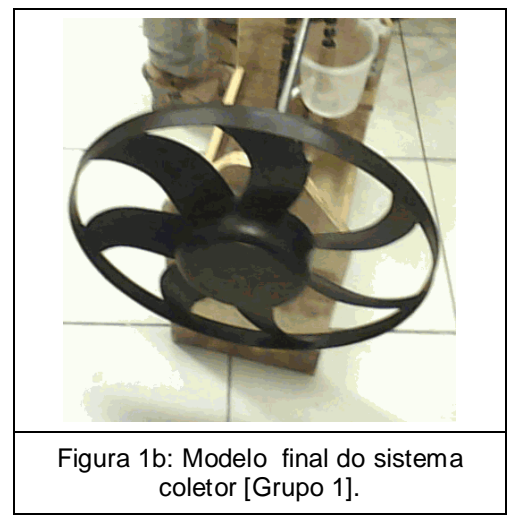

A maioria dos grupos teve concepção do sistema coletor eólico extremamente similar ao grupo 1. Desse modo, optaram por um sistema de pás adquirido de 
desmontagem de ventiladores padrão ou em lojas de materiais recicláveis.

\subsubsection{O MECANISMO ELEVATÓRIO DE ÁGUA}

Para o mecanismo elevatório de água houve maior criatividade e diversidade de soluções.

Como mecanismo para elevar a água, o grupo 1 optou por um esquema apresentado nas figuras $2 a \mathrm{e} 2 \mathrm{~b}$.

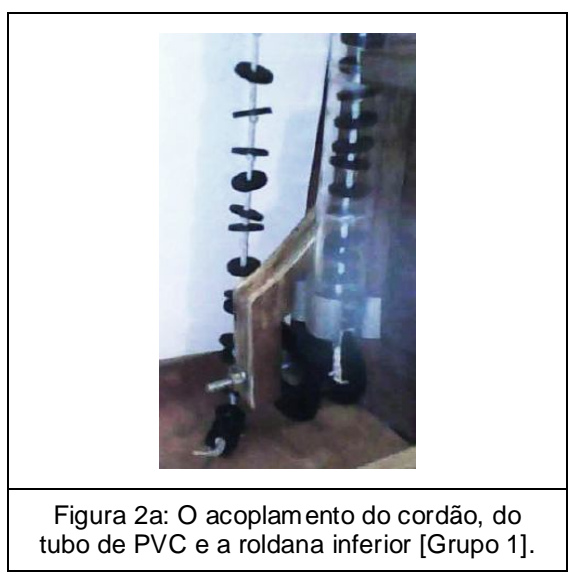

Inicialmente, um cordão contendo uma série de filamentos de borracha flexível percorre um circuito com parte do movimento perpassando um tubo transparente. A Figura $2 \mathrm{~b}$ mostra uma vista geral do par de roldanas superior afixadas na estrutura de madeira.

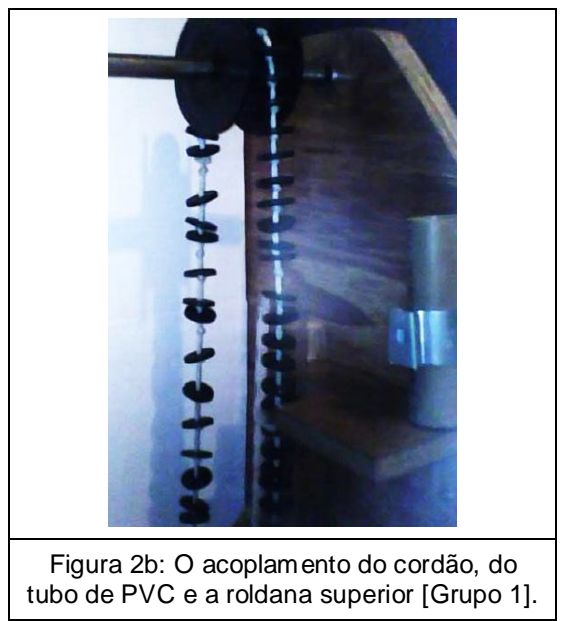

e-xacta, Belo Horizonte, v. 6, n. 1, p. 9-18. (2013). Editora UniBH.

Disponível em: www.unibh.br/revistas/exacta/
Outra ilustração que valorizou a criatividade e a inovação foi realizada pelo grupo 5. A evolução do mecanismo elevatório está descrita a seguir.
As primeiras ideias do projeto envolveram um estudo de mecânica, no qual verificamos como funciona o sistema de duas ou mais polias. Ainda, fizemos buscas sobre o modo como se extrai o petróleo e como aplicar tais princípios a um pequeno pistão no interior da bomba de sucção. No princípio houve a simulação no AutoCAD (um software do tipo CAD - computer aided design ou desenho auxiliado por computador) e, posteriormente, elaboramos a confecção do projeto físico. [...] A segunda etapa de planejamento foi a mais difícil: como projetar a ideia e o conceito da pesquisa no funcionamento da física e como montar as primeiras peças (GRUPO 5).

No memorial, o grupo descreveu a construção de uma estrutura em madeira, a qual, porém, não suportou os ciclos, gerando trepidação e travamento dos eixos. A opção foi realizar a "[...] alteração pelo alumínio e outras fixações mais resistentes, o que acabou com o problema" (GRUPO 5).

A figura 3a ilustra a visão geral do sistema elevatório.

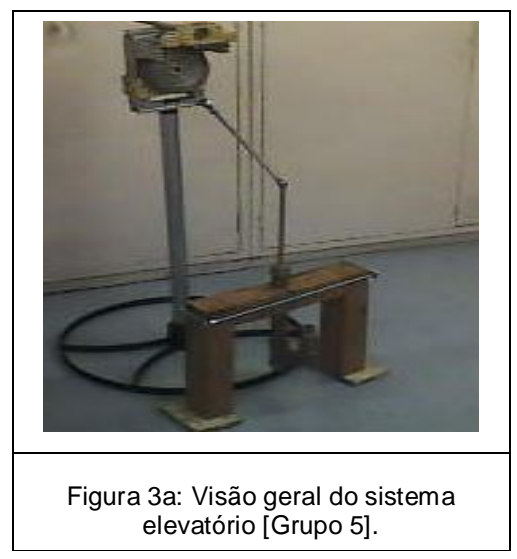

Para a montagem da bomba, o referido grupo acoplou uma polia a um eixo excêntrico, conforme ilustra a Figura 3a. As figuras $3 b$ e $3 c$ destacam os detalhes de montagem da polia, do excêntrico e da tubulação para realizar o trabalho elevatório da água. 


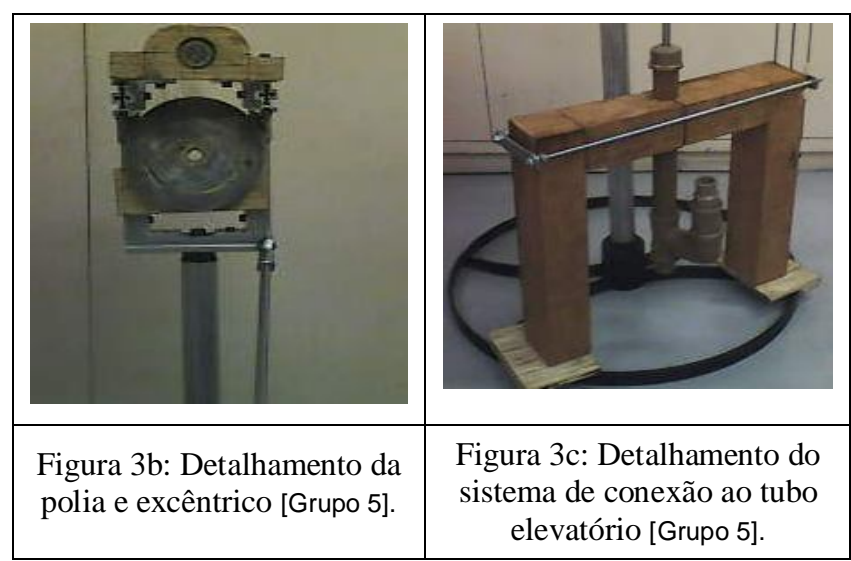

Como conclusão, o memorial destacou que na prática "[...] o dispositivo funcionava lentamente e com dificuldades no momento da partida, o que foi resolvido por lubrificação do eixo e do pistão com vaselina" (GRUPO 5).

\subsection{CONSIDERAÇõES FINAIS}

Em face das exposições realizadas, é objeto desta seção responder à questão proposta no presente relato: como e em que medida o projeto educativo auxilia o desenvolvimento de competências tão necessárias e essenciais na educação do ensino superior?

Usualmente, a disciplina de Física Geral e Experimental III propicia a vivência de conceitos teóricos, vinculados principalmente aos tópicos específicos da área, através da realização de experiências estruturadas e controladas, associadas à produção de um relatório para discriminar os resultados experimentais e compará-los com os parâmetros esperados pela superposição da teoria.

Porém, o projeto delineado no presente texto foi além dos tópicos descritos no plano de ensino da referida disciplina, propondo contribuições situadas na perspectiva intradisciplinar. As soluções apresentadas pelos grupos não foram superadas somente por tentativa e erro. No Memorial houve frequente menção à busca de informações e conhecimentos da disciplina de Física, desenvolvidos ao longo do curso, assim como em vivências cotidianas e anteriores, o que permitiu o diálogo entre a teoria e a prática.

A análise das etapas do projeto, desenvolvidos no Memorial, permitiu observar que a mobilização dos conceitos se aliou à necessária diversidade de registros, permeando uma riqueza de detalhes, o que favoreceu 0 aprimoramento dos conteúdos procedimentais e atitudinais. O memorial, um recurso de pesquisa, favoreceu $\mathrm{o}$ projeto educativo em questão a se constituir como ferramenta para a construção entre conhecimentos e competências.

A concepção inventiva do projeto se evidenciou pela busca e estabelecimento de metas, próprios da subjetividade humana, que permitem ao criador selecionar a informação necessária, dirigir o olhar para a realidade e definir as metas do projeto, descobrindo possibilidades, antecipando situações, elaborando uma ocorrência de aprendizagem para além dos conceitos.

Nos resultados obtidos pelos grupos, observou-se que o sistema de captação da energia eólica dos diversos grupos praticamente se limitou a um sistema de hélices padronizados e comercializadas, obtido de modo imediato no mercado.

Porém, a dimensão criadora, que Marina (1995) destaca como uma manifestação essencial da inteligência humana, ficou evidenciada no mecanismo elevatório de água. A variedade de soluções e eficiência, que oscilou entre uma altura de poucos centímetros até $1,5 \mathrm{~m}$, permitiu aos grupos superar o desafio inicialmente proposto pelo projeto educativo, favorecendo um quadro de articulação entre conteúdos e competências.

Machado (2009) aponta que as instituições escolares devem visar ao desenvolvimento de competências pessoais e coletivas. Em muitos sentidos, os 
resultados expressos nesse projeto educativo favorecem a associação natural com o trabalho do engenheiro, que é por muito ligado ao desenvolvimento e aplicação de projetos técnicos, porém em um contexto complementar, comunicativo e interativo com os demais colegas de trabalho.

Atualmente, Machado (2004) aponta que o conhecimento se tornou um bem revalorizado, principalmente no campo de trabalho. Desse modo, o contexto relacional entre conhecimentos e competências, mobilizados pelos alunos por meio de reflexão e busca de soluções do projeto educativo, favoreceu e promoveu a interatividade e autonomia do aluno, complementando e ampliando as abordagens, alavancando $o$ processo de ensino e de aprendizagem, dois pólos educacionais que representam o cerne das ocupações profissionais da sociedade futura.

\section{REFERÊNCIAS}

BOISOT, M. Knowledge Assets. Oxford, 2000.

BOUTINET, J. P. Antropologia do Projeto. Porto Alegre: ArtMed, 2002.

BRASIL. Diretrizes Curriculares Nacionais Gerais para a Educação Profissional de Nível Tecnológico: Parecer do Conselho Nacional de Educação/Conselho Pleno, n. 29. Brasília: Distrito Federal, 2002.

DELORS, J. Os quatro pilares da educação. In: DELORS, J. Educação: um tesouro a descobrir. São Paulo, Cortez, 2003.

KRASILCHIK, M. Docência no Ensino Superior: tensões e mudanças. Cadernos de Pedagogia Universitária. USP: 2008.

MACEDO, L. Jogo e Projeto: Irredutíveis e Complementares. In: ARANTES, A. A. Jogo e Projeto. São Paulo: Summus, 2006.

MACHADO, N. J. Conhecimento e valor. São Paulo: Moderna, 2004.
Qualidade. São Paulo: Escrituras, 2009.

MARINA, J. A. Teoria da inteligência criadora. Lisboa: Caminho da Ciência, 1995.

PORTALBRASIL. Acesso à universidade: ENADE. Disponível em: <http://www.brasil.gov.br/sobre/ educacao/acesso-a-universidade/enade $>$. Acesso em: Acesso em 15 out. 2012.

PORTAL DA EDUCAÇÃO. Disponível em: $<$ http://www.aaaPortal Educação.mht>. Acesso em 12 set 2009.

POZO, J. I. A Solução de Problemas: Aprender a Resolver, resolver para aprender. Porto Alegre: ArtMed, 1998.

ROSZAK, T. O culto da informação. São Paulo: Brasiliense, 1988. 